MS18. Thermoelectric

materials - from fundamental

science to applications
MS19. Topology of crystal

structures
Chairs: Davide Proserpio, Tonči Balić-Žunić

\section{MS18-P1 Interplay between structural transitions and thermoelectric properties in a Mn hollandite}

Sylvie Hébert ${ }^{1}$, Jesus Prado Gonjal ${ }^{1}$, Hidefumi Takahashi ${ }^{1}$, Denis Pelloquin $^{1}$, Antoine Maignan ${ }^{1}$

1. Laboratoire CRISMAT, UMR6508 CNRS et ENSICAEN, 6 Bd du Maréchal Juin, 14050 Caen Cedex, France

email: sylvie.hebert@ensicaen.fr

$\mathrm{Na}_{\mathrm{CoO}}$ and misfits are still the best $\mathrm{p}$ type thermoelectric oxides, with the combination of a large Seebeck coefficient, together with a metallic behaviour at $300 \mathrm{~K}$, and small values of thermal conductivities [1-3]. Their unique thermoelectric properties come from the presence of $\mathrm{CoO}_{2}$ layers made of edge shared $\mathrm{CoO}_{6}$ octahedra, with $\mathrm{Co}^{2+}$ and $\mathrm{Co}^{4+}$ in low spin states. New families of oxides have since then been investigated to find new potential thermoelectric materials. Among them, hollandites present an interesting crystallographic structure with (i) ribbons made of edge shared octahedra, and (ii) the presence of tunnels, in which large cations can be inserted. Several hollandites have been investigated, with both $\mathrm{p}$ and $\mathrm{n}$ type doping, and large power factors have been observed [4-5]. In this poster, the results obtained in the case of $\mathrm{Ba}_{\mathrm{Xn}} \mathrm{Mn}_{8} \mathrm{O}_{16}$ hollandite will be presented, with the evidence of a structural transition at high $\mathrm{T}$. The impact of this structural transition on the transport properties will be discussed.

[1]: I. Terasaki, Y. Sasago and K. Uchinokura, Phys. Rev. B56, R 12685(1997).

[2]: K. Takahata, Y. Iguchi, D. Tanaka, and T. Itoh, I. Terasaki, Phys. Rev. B61, 12551 (2000).

[3] : S. Hébert, W. Kobayashi, H. Muguerra, Y. Bréard, N. Raghavendra, F. Gascoin, E. Guilmeau, A. Maignan, Physica Status Solidi A210, 69 (2013).

[4] : W. Kobayashi, S. Hébert, O. Pérez, D. Pelloquin, A. Maignan, Phys. Rev. B79, 085207 (2009).

[5]: A. Maignan, O I. Lebedev, G. Van Tendeloo, C. Martin, S. Hébert, Phys. Rev. B82, 035122 (2010).

J. Prado Gonjal, Present address : University of Reading H. Takahashi, Present address : Nagoya University

Keywords: Oxides, hollandites

\section{9-P1 Crystal chemistry of Al-phosphate minerals with complex H-bond networks}

Francesco Capitelli ${ }^{1}$, Giancarlo Della Ventura ${ }^{2}$, Fabio Bellatreccia $^{2}$, Maria Rosaria Ghiara ${ }^{3}$, Manuela Rossi ${ }^{3}$, Emanuela Schingaro ${ }^{4}$, Gennaro Ventruti ${ }^{4}$, Angela Altomare ${ }^{5}$, Michele Saviano ${ }^{5}$

1. Istituto di Cristallografia - CNR Monterotondo (Rome, Italy)

2. Dipartimento di Scienze, Università Roma Tre (Rome, Italy)

3. Real Museo Mineralogico and Dipartimento di Scienze della Terra dell'Ambiente e delle Risorse, Università Federico II Naples (Naples, Italy)

4. Dipartimento di Scienze della Terra e Geoambientali, Università di Bari (Bari, Italy)

5. Istituto di Cristallografia - CNR Bari (Bari, Italy)

\section{email: francesco.capitelli@ic.cnr.it}

The $\left(\mathrm{PO}_{4}\right)$ oxyanion combines with over 30 elements to form natural phosphates, which are among the most complex and variegated compounds in all the mineral world, displaying a large number of recognized phases (about 300), most of them featuring hydrogen as hydroxyl groups and water molecules. Thus, hydrogen bond displays a crucial role in stabilizing the hydroxy-hydrated phosphate frameworks, providing the additional bond-valence contribution to the anions. Hence, the oxygen atoms of $\left(\mathrm{PO}_{4}\right)$ groups easily interact with neighbor cationic environments in the structure. For this reason, many phosphates are characterized by the presence of an intricate network of $\mathrm{O}-\mathrm{H}$...O interactions, joining the polyhedral units and making up the three dimensional framework (Huminicki \& Hawthorne, 2002). In this sense, the study of such complex structures is achieved by means of Single-Crystal X-Ray Diffraction, with the contribute of powder FTIR spectroscopy, being the latter a powerful tool for the study of hydrogen in minerals, especially in presence of high $\mathrm{OH} / \mathrm{H}_{2} \mathrm{O}$ contents.

In this work, we present the structure investigations of selected aluminum phosphates: vauxite $\mathrm{FeAl}_{2}\left(\mathrm{PO}_{4}\right)_{2}(\mathrm{OH})_{2} \cdot 6 \mathrm{H}_{2} \mathrm{O}, \quad$ wardite $\mathrm{NaAI}_{2}\left(\mathrm{PO}_{4}\right)_{2}(\mathrm{OH})^{2} \cdot 2 \mathrm{H}_{2} \mathrm{O}, \quad$ wavellite $\mathrm{Al}_{3}\left(\mathrm{PO}_{4}\right)_{2}(\mathrm{O} H, \mathrm{~F})_{3} \cdot 5 \mathrm{H}_{2} \mathrm{O}$, augelite $\mathrm{Al}_{2}\left(\mathrm{PO}_{4}\right)(\mathrm{OH})_{3}$, whiteite $\mathrm{CaFeMgAl}_{2}\left(\mathrm{PO}_{4}\right)_{4}(\mathrm{OH})_{2} \bullet 8 \mathrm{H}_{2} \mathrm{O}$ (Ventruti et al., 2015, and references therein). Main crystallographic features (bonds, angles, interactions) were examined and compared with those obtained from phosphate literature, and the networks of hydrogen bonds were further analyzed according to the Libowitzky (1999) relationship, for the range of D-H...A bond systems in the structure, in order to compare results of $\mathrm{OH}$ frequencies from FTIR spectra with those observed by X-ray refinement.

\section{References}


Huminicki, D.M.C. \& Hawthorne, F.C. (2002): The crystal chemistry of phosphate minerals. Reviews in Mineralogy and Geochemistry 48, 123-253.

Ventruti G., Monno A., Schingaro E., Lacalamita M., Della Ventura G., Bellatreccia F., Cuocci C.. Capitelli F. Structure refinement and vibrational spectroscopy of vauxite from the type locality, Lallagua (Bolivia). Canadian Mineralogist, in press.

Libowitzky, E. (1999): Correlation of O-H stretching frequencies and $\mathrm{O}-\mathrm{H} . . \mathrm{O}$ hydrogen bond lengths in minerals. Monatshefte für Chemie 130, 1047-1059.

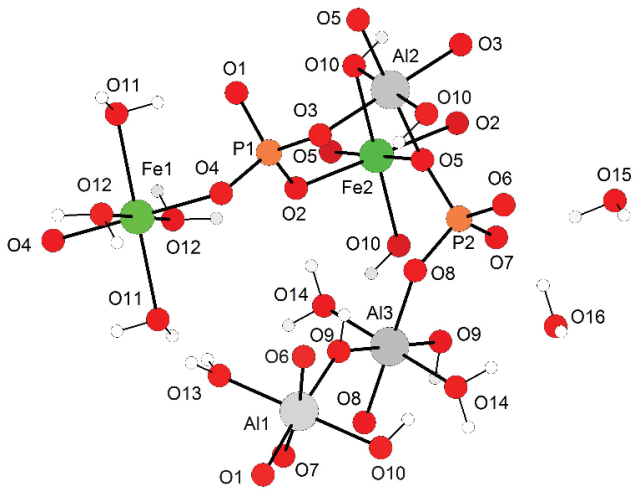

Figure 1. Cationic and anionic environments for vauxite.

Keywords: phosphates; structure refinement; hydrogen bonds; FTIR

\section{MS19-P2 Constructing new porous materials based on polymeric cage metallosiloxanes}

Alexander A. Korlyukov ${ }^{1}$, Anna V. Volozhanina ${ }^{1}$, Olga I.

Shchegolikhina ${ }^{1}$, Alexei N. Bilyachenko ${ }^{1}$, Boris G. Zavin ${ }^{1}$, Nataliya V. Sergienko ${ }^{1}$

1. A.N. Nesmeyanov Institute of Organoelement Compounds, 119991, Russian Federation, Moscow, Vavilova Str., 28

email: alex@xrlab.ineos.ac.ru

We report on structural features and electronic properties of polymeric metallasiloxanes obtained by X-ray studies, magnetic measurements and theoretical calculations. Polymer structure of metallasiloxanes (MOS) under discussion composed from cage monomeric units containing various number of transition metals $(\mathrm{Cu}$, $\mathrm{Ni}, \mathrm{Mn}, \mathrm{Fe}$ ) interconnected by alkali-metal ions and weak interatomic interactions (hydrogen bonds or staking interactions). The type of supramolecular architecture $(1 \mathrm{D}, 2 \mathrm{D}$ or $3 \mathrm{D}$, see Figure 1) can be controlled by variation of ionic radii of alkali metal, the nature of solvent used for crystallization and addition of chelating ligands. These factors also affect the size of MOS monomeric units which can include 2-11 transition metal atoms forming metalloxide core partially coated by cyclic and acyclic siloxanolate ligands. Magnetic measurements have shown the pronounced ferro- and antiferromagnetic properties depending on number and the nature of transition metal in MOS core.

It was demonstrated by powder X-ray diffraction (XRD) and XAFS studies that polymer structure established at low temperature by single crystal XRD in the most of cases retained at room temperature. The role of metallosiloxanes as structure building units, the topology of resulting nets and accessibility of the voids were analyzed. In addition, the strength of coordination bonds and weak interatomic interactions responsible for the stabilization of polymer structures were estimated in terms of R. Bader's QTAIM theory.

Authors are grateful to Prof. Yan Zubavichus (Kurchatov Center for Synchrotron Radiation and Nanotechnology) for help with XAFS and single-crystal synchrotron studies. The work was supported by Russian Science Foundation (grant 14-23-00231).
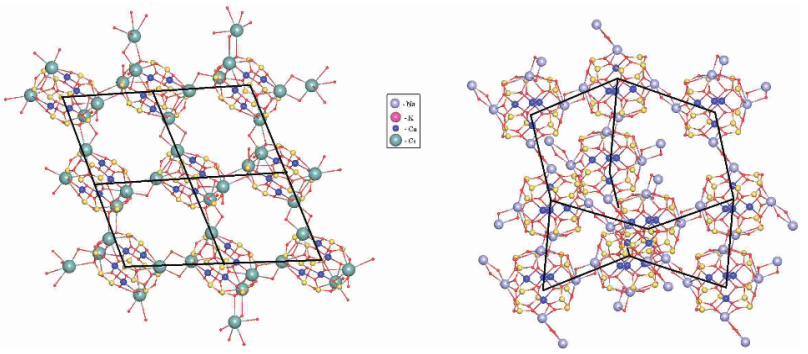

Figure 1. Fragments of the sql and dia nets in the structures of sodium (left) and cesium (right) coppersiloxanes

Keywords: metallasiloxanes, coordination polymers, structure building unit, magnetic properties, QTAIM studies. 